\title{
GESTÃO DO PATRIMÔNIO E POVOS INDÍGENAS: A NECESSIDADE DE UMA ABORDAGEM INCLUSIVA E INTERCULTURAL
}

\author{
MARCELO MARQUES MIRANDA ${ }^{1}$ \\ UNIVERSIDADE DE LEIDEN
}

\begin{abstract}
RESUMO: Os mecanismos de gestão do patrimônio em países anteriormente sob o domínio ocidental tendem ainda a seguir aproximações que ignoram os valores que os povos indígenas atribuem a objetos e sítios arqueológicos nos seus territórios ancestrais. Além disso, estes mecanismos funcionam como uma ferramenta para desvincular as comunidades de participar no processo de proteção e gestão de um patrimônio que reclamam seu, desrespeitando-se assim os seus direitos humanos e coletivos. Com base no exemplo do povo Camëntsá, são apontados alguns dos motivos desse distanciamento e sugerido que uma abordagem colaborativa $e$ intercultural da gestão do patrimônio seja mais adequada, pois está baseada numa compreensão inclusiva do patrimônio e reconhece que não só este é usado como forma de resistência, como também está sujeito à interpretação de diferentes grupos. No caso específico da arqueologia, é necessário expandir os horizontes da disciplina, reconhecendo a relação dos povos indígenas com o passado material, e trabalhar de uma forma em que pesquisadores, comunidades indígenas e instituições governamentais colaborem verdadeiramente.
\end{abstract}

PALAVRAS-CHAVE: arqueologia; museologia; descolonização; colaboração; direitos humanos.

ABSTRACT: Heritage management mechanisms in countries formerly under Western rule still tend to follow approaches which ignore the values that Indigenous peoples ascribe to archaeological objects and sites in their ancestral territories. In addition, these mechanisms function as a tool to disengage communities from participating in the process of protecting and managing a heritage they claim their own, thus disrespecting their human and collective rights. Based on the case of the Camëntsá people, I point out some of the reasons for this detachment and suggest that a collaborative and intercultural approach to heritage management is more appropriate, since it is based on an inclusive understanding of heritage and recognizes that not only is this used as a form of resistance, but it is also subject to the interpretation of different groups. In the specific case of archaeology, it is necessary to expand the horizons of the discipline by recognizing the relationship of Indigenous peoples with the material past, and working in a way in which researchers, Indigenous communities and government institutions truly collaborate.

KEYWORDS: archaeology; museology; decolonization; collaboration; human rights.

\footnotetext{
${ }^{1} \mathrm{PhD}$ Researcher. Faculdade de Arqueologia da Universidade de Leiden. E-mail: marcelo.m.miranda@hotmail.com .
} 


\section{Introdução}

A atual e globalizada noção de patrimônio tem recebido numerosas críticas por parte de povos indígenas em todo o mundo por promover uma narrativa nacionalista e elitista e pela sua inépcia em compreender e aceitar que objetos, edifícios e lugares têm valor além de sua materialidade. Um documento enviado em 2015 ao Mecanismo de Peritos sobre os Direitos dos Povos Indígenas (IWGIA \& FPP) dava conta da problemática diferenciação entre cultura e natureza, da inexistência de consentimento livre, prévio e informado, assim como da falta de reconhecimento e envolvimento dos povos indígenas na implementação da Convenção do Patrimônio Mundial, entre outras questões que afetam os seus direitos. Tal documento demonstra que existe a preocupação por parte dos povos indígenas em proteger e conservar o patrimônio, e exigir das autoridades os seus direitos, informação e participação nesse processo. No entanto, estas devem reconhecer que os povos indígenas têm uma interpretação diferente do patrimônio e de como a sua proteção e conservação devem ser conduzidas. Estas últimas afastam-se bastante dos conceitos ocidentais centrados na materialidade, na exploração econômica, nos dualismos e exotismos, ou em um "fetichismo de objetos" resultante do estabelecimento de marcos legais e sua implementação (GNECCO; AYALA, 2010 , p. 24). Os museus são talvez o melhor exemplo de como as culturas dos povos indígenas têm sido abordadas numa perspectiva etnocêntrica e colonialista, tendendo a ser exotizadas e subjugadas. Com base em valores estéticos e materialistas ocidentais, tal percepção de uma cultura obstrui a importância do contexto social e do uso dos objetos (KREPS, 2006). Consequentemente, produz uma "violência epistémica" (LONDOÑO, 2012, p. 737), isto é, a cultura hegemônica impõe um significado diferente às culturas subordinadas.

Por estas razões, para que o patrimônio dos povos indígenas possa ser efetivamente protegido e conservado, em primeiro lugar ele deve ser compreendido de maneira holística. Assim, as políticas culturais precisam conciliar as próprias cosmovisões com a participação ativa das comunidades, incluindo as preocupações, expectativas e contestações dessas e não procedendo à imposição de uma noção estatal de patrimônio (GNECCO; AYALA, 2010, p. 24). Além disso, estas medidas devem fazer parte de um processo justo, independente, imparcial, aberto e transparente entre as comunidades e as autoridades locais e nacionais (GILBERT, 2010). Tal está plasmado na Declaração das Nações Unidas sobre os Direitos dos Povos Indígenas (Nações Unidas, 2007) e será este o caminho para respeitar a perspectiva dos povos indígenas acerca do patrimônio. No entanto, os atuais mecanismos de gestão do patrimônio não estão preparados para resolver estas preocupações, pois não comportam noções dissidentes que ameaçam a narrativa nacional. Por conseguinte, são contestados pelos povos indígenas, uma vez que estes 
não lhes conferem acesso e autoridade sobre um patrimônio do qual se consideram detentores e que julgam necessário para manter a identidade e o particular sentido de pertença ao território.

Por outro lado, os povos indígenas têm contribuído para o desenvolvimento do conceito de patrimônio nas últimas décadas devido às suas cosmovisões e à relação com a natureza - tanto em um nível físico como metafísico - que têm confrontado e enriquecido uma noção de origem europeia sobre como o patrimônio deve ser gerido e preservado. Contrastando com as concepções duais da lógica do pensamento ocidental - refletidas na Convenção para a Proteção do Patrimônio Mundial, Cultural e Natural (UNESCO, 1972) - segundo os povos indígenas, natureza e cultura são elementos indissociáveis. Isso significa que objetos e monumentos, plantas e animais, o mundano e o espiritual estão sempre interligados, isto é, "têm vida para além da manifestação biológica" (ARAÚJO, 2017, p. 54). Existe uma relação recíproca entre as pessoas e os objetos, e tratá-los como "coisas" passíveis de exibição, expropriação e apropriação por um Estado, que as explora para os mais diversos fins, pode não ser admissível desde a perspectiva dos povos indígenas (LONDOÑO, 2012, p. 733-734). Tais objetos evocam emoções e memórias, transbordam lugares e tempos particulares, e requerem assim ser entendidos em um sentido mais amplo (GNECCO; HERNÁNDEZ, 2010 , p. 96). Aliás, é comum que certos lugares sejam considerados de valor patrimonial, apesar da ausência de elementos tangíveis significativos. Neste caso, os elementos naturais não são abordados somente desde a perspectiva da conservação da biodiversidade - ainda que esta seja também fundamental para os povos indígenas - e, muito menos, desde um ponto de vista estético (UNESCO, 1972, art. $2^{\circ}$ ). A falta de elementos monumentais nestes sítios transforma os procedimentos de gestão patrimonial numa tarefa complexa, na medida em que os mecanismos de proteção e conservação do patrimônio existentes nos países latino-americanos - e na Colômbia especificamente - estão baseados nas culturas monumentais europeias (RODRIGUEZ URIBE; RODRIGUEZ URIBE, 2013).

O Bëngbe Benacheng é um projeto colaborativo e intercultural de análise e gestão do patrimônio cultural do povo Camëntsá na Colômbia iniciado em maio de 2017. Situado em um marco de investigação+ação, este projeto visa não só a abordar o patrimônio de forma crítica, como também a criar mecanismos de proteção e gestão que sejam mais compreensivos e inclusivos, através de um trabalho contínuo de colaboração entre pesquisadores e comunidade indígena, no qual tanto a cosmovisão camëntsá como os seus direitos humanos e coletivos são respeitados. No idioma camëntsá, Bënge Benacheng significa "nossos caminhos". Este termo está relacionado com a forma tradicional camëntsá de entender a vida e a natureza, assim como a gestão e conservação do território e seus recursos. Os Camëntsá, portanto, seguem os caminhos traçados pelos seus antepassados. Neste sentido, é fundamental que o povo Camëntsá seja empoderado através da pesquisa. $O$ projeto está 
dividido em duas áreas inter-relacionadas: proteção e conservação de sítios sagrados e arqueológicos, e interpretação e exibição da cultura material em museus. Ambas as áreas são abordadas de forma integral e relacionadas com dois elementos mais amplos que são essenciais para compreender o patrimônio cultural camëntsá: a língua nativa e o território ancestral.

\section{Contexto}

Este projeto tem como foco principal o caso do povo Camëntsá e Uaman Tabanoc, seu lugar de origem (CABILDO CAMËNTSÁ, 2012). Hoje em dia conhecida como Vale de Sibundoy, esta região no sudoeste da Colômbia desempenha um papel essencial na identidade, história e cosmovisão dos Camëntsá. No entanto, durante o processo de colonização, estes se viram privados das suas terras e foram forçosamente deslocados para a periferia. A área central da aldeia de Sibundoy, um lugar agora identificado como Parque da Interculturalidade, tem grande importância para os Camëntsá, uma vez que é um ponto de encontro tradicional, associado à memória dos antepassados e anciãos, e ao sofrimento sentido por estes às mãos das missões evangelizadoras, sobretudo através dos atos de flagelação e humilhação pública (GÓMEZ LÓPEZ, 2005). Em virtude dos últimos motivos, é identificado pelos Camëntsá como Lamentacionënts - Sítio das Lamentações. No entanto, este lugar é propriedade pública, e o governo local organiza eventos que não estão relacionados com a cultura camëntsá, como a venda de produtos ou uso de música por parte dos colonos durante as celebrações sagradas, o que ofende o significado que tal povo atribui ao referido lugar. Para além da forte simbologia cristã que domina o lugar, existem também problemas com outras comunidades indígenas que só recentemente migraram para o vale e tentam obter a concessão de resguardos com base numa suposta conexão ancestral com este lugar. A existência de vários grupos com diferentes agendas e percepções do território invariavelmente gera conflitos e contestação.

O povo Camëntsá é formado por cerca de 9.000 indivíduos que vivem na sua maioria em Sibundoy, mas também nos municípios de San Francisco, Mocoa, Villagarzon e Orito - no departamento de Putumayo bem como em Bogotá (CABILDO CAMËNTSÁ, 2012). Em cada um destes municípios, os Camëntsá estão representados institucionalmente por um cabildo, uma entidade pública especial, detentora de uma organização sociopolítica tradicional, sendo eleitos e reconhecidos por ela. O povo Camëntsá tem também seu próprio resguardo, território reconhecido oficialmente, com uma área total de 3.252 hectares. Comparando com o seu território ancestral, trata-se obviamente de uma extensão bastante limitada. 
Figura 1 - Mapa de Sibundoy e do resguardo Camëntsá

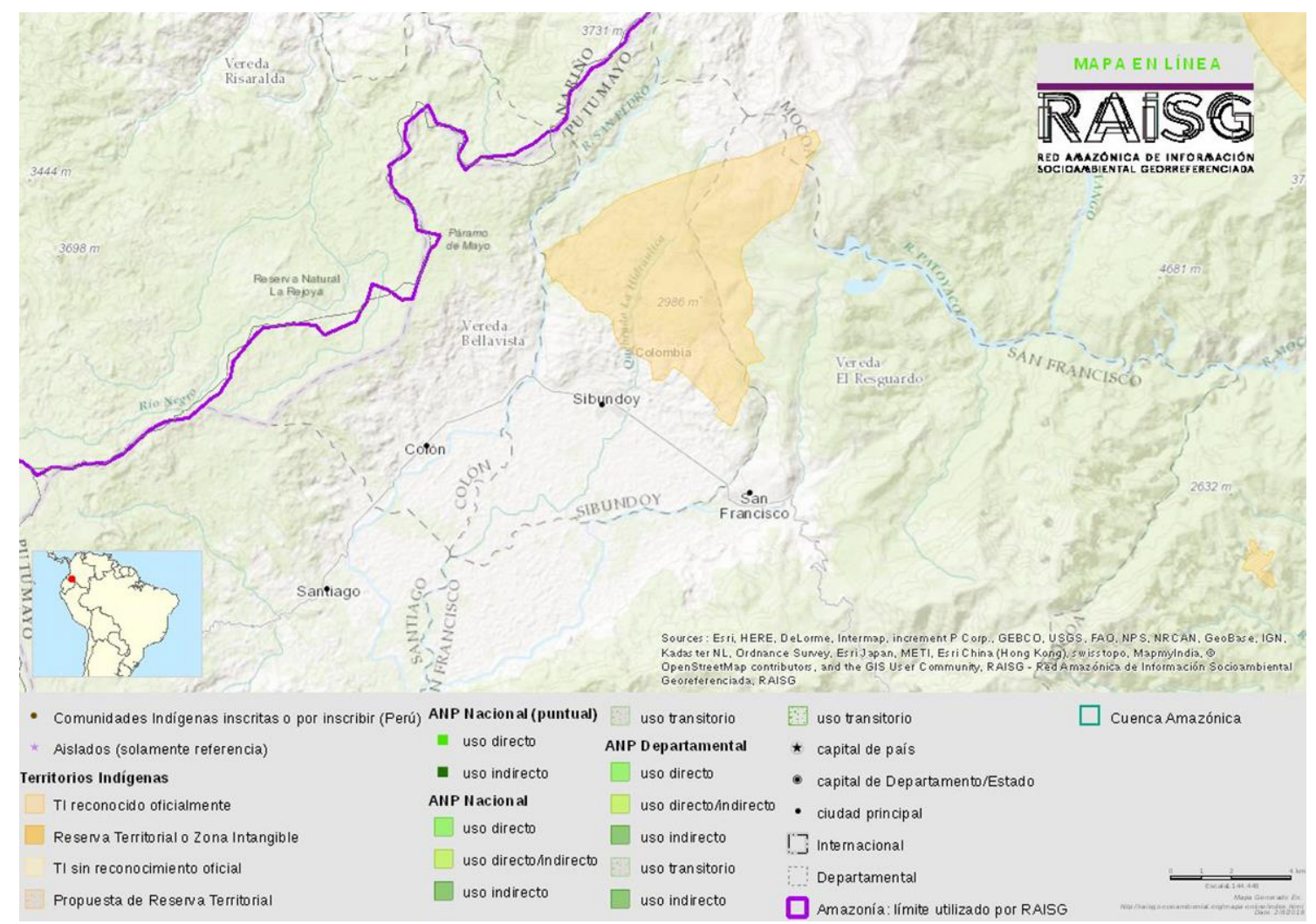

Fonte: Rede Amazônica de Informação Socioambiental, RAISG.

Os Camëntsá falam um idioma próprio com o mesmo nome, o qual não tem vínculo com qualquer outro idioma ou dialeto conhecido. Com as guerras da conquista espanhola e a propagação de doenças desconhecidas até então, os Camëntsá foram dizimados quase por completo, passando de uma população com números equiparáveis aos atuais para, em finais do século XVII, ser reduzida a apenas 150 indivíduos. Já no século XIX, a indústria da borracha e missões evangelizadoras deixariam os Camëntsá uma vez mais à beira da extinção física e cultural (CABILDO CAMËNTSÁ, 2012). A colonização afetou o povo Camëntsá e seu território em termos econômicos e ambientais em vários níveis, alguns deles irreversíveis, como a drenagem da lagoa que existia no vale (iniciada pelos frades capuchinos), a deflorestação da zona montanhosa e a contaminação dos solos devido ao uso de adubos químicos. Estes interligam-se com processos culturais que eventualmente desapareceram ou sofreram fortes mudanças e dos quais só restam histórias (MAVISOY, 2008). Devido à sua localização isolada, o povo Camëntsá tem sido também vítima de violência e migração forçada, resultado da presença de grupos armados ilegais e narcotraficantes. Segundo dados da Agência da ONU para Refugiados (ACNUR, 2011), entre os anos de 2003 e 2008, 3.532 indivíduos foram forçosamente deslocados - mais de $70 \%$ de uma população que o mesmo documento 
indica ser de 4.879 - e 3 indivíduos foram assassinados. Todos estes processos afetaram e afetam de forma evidente a estrutura social e cultural de um povo, deixando também o seu território ancestral fragmentado.

Uaman Tabanoc é considerado o lugar de origem do povo Camëntsá e onde este tem permanecido e se desenvolvido ao longo do tempo. Todas as atividades culturais da comunidade giram ao redor de espaços com um grande valor histórico e espiritual. Ao celebrar o Bëtscnaté - Dia Grande ou Dia do Perdão -, os amigos e familiares voltam a se reencontrar e juntos percorrem estes lugares importantes do território ancestral, agradecendo à Tsabatsána Mamá - Terra Mãe - pela vida, e recordando os antepassados. A estes se dedicam rituais durante o Bëtscnaté, como forma de homenagem pelos seus ensinamentos (CABILDO CAMËNTSÁ, 2012). Tal cerimônia não teria sentido fora deste lugar porque, mais que uma expressão religiosa, é uma demonstração de pertencimento a um território. A cruz situada no centro do parque é vista pelos Camëntsá não como símbolo da fé cristã, mas como representação do sagrado, da reconciliação, de um povo fortemente enraizado no seu território, assim como do sofrimento ali vivido pelos antepassados diante das missões evangelizadoras. Apesar da colonização e da apropriação deste espaço por diferentes atores que têm ao longo do tempo impingido suas diferentes maneiras de ver o mundo, este espaço, assim como todo o território ancestral, continua a ser considerado como sagrado para o povo Camëntsá.

Figura 2 - Parque da Interculturalidade ou Lamentacionënts

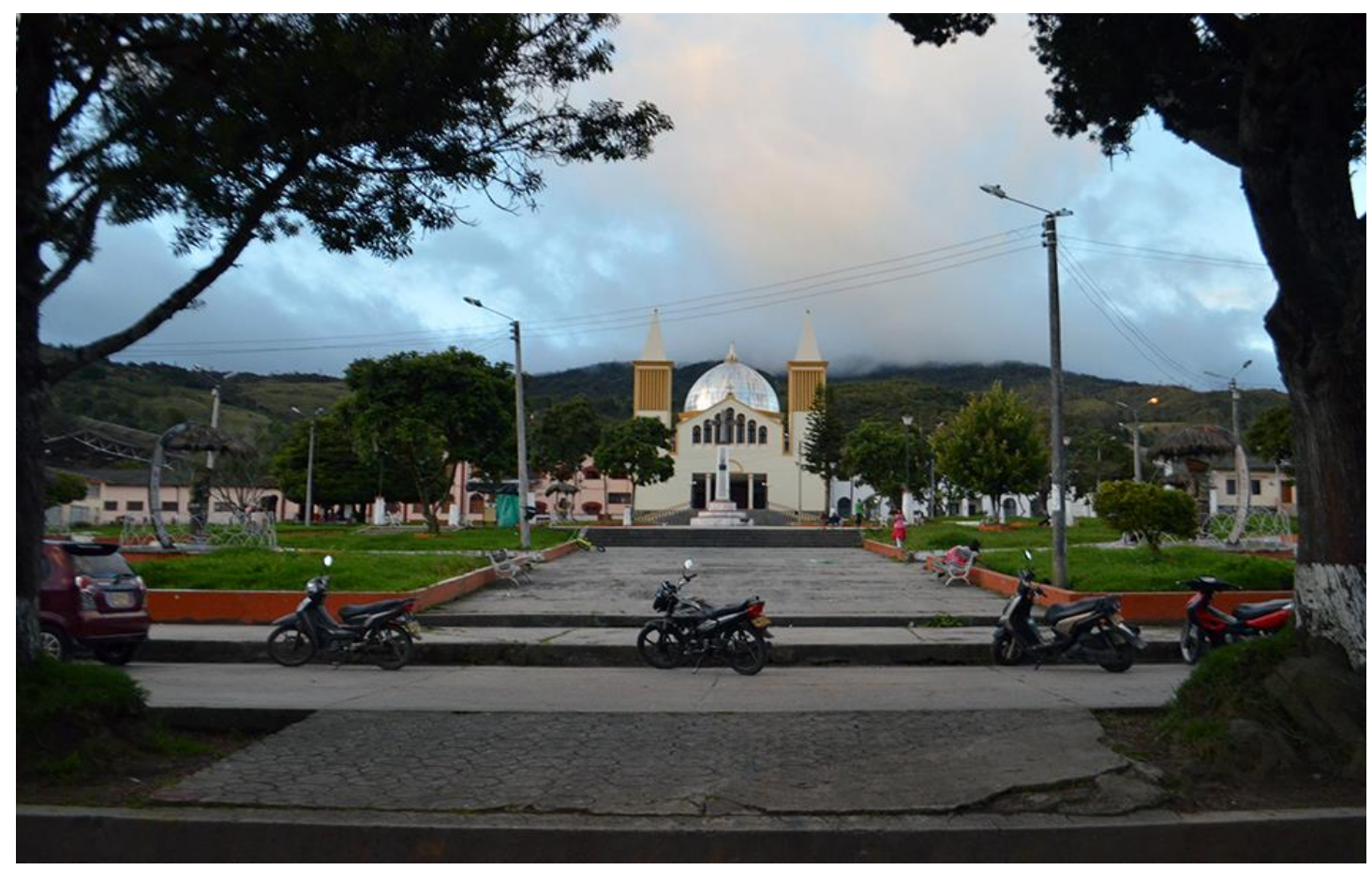

Fonte: Jully Acuña, 2017. 


\section{O patrimônio sob diferentes perspectivas}

Um dos grandes problemas da atual e globalizada noção de patrimônio é a total desarticulação que ela estabelece entre as comunidades e o seu patrimônio. Apelidado de "Discurso Autorizado do Património" (SMITH, 2006), esta noção remete a um passado que deve ser conservado por especialistas. De acordo com Smith (2006, p. 29), aplicar termos como "o passado" para nos referirmos ao patrimônio afasta-nos do verdadeiro trabalho emocional e cultural que esse passado tem para os indivíduos e comunidades de hoje em dia, já que é um elemento fundamental na construção das suas identidades. O papel dos especialistas é também legitimado pelo fato de eles serem vistos como os únicos indivíduos com o conhecimento e a capacidade de proteger e transmitir o patrimônio às futuras gerações, limitando ou impedindo assim o seu acesso e uso ativo por parte de outros atores sociais. Esse trabalho e autoridade são transferidos para arquitetos, historiadores e arqueólogos, que passam a funcionar como guardiões do passado para que as presentes e futuras gerações possam ser propriamente educadas e informadas acerca do seu valor (p. 29-30). O surgimento desta noção de patrimônio insere-se no contexto dos nacionalismos europeus do século XIX, que concebem a relação entre identidade e patrimônio a partir da ideia de nação. Ademais, tal concepção de patrimônio é também fortalecida pelos discursos nacionalistas subjacentes às disciplinas da arqueologia e história, assim como pelos de universalidade dos valores do patrimônio espelhados na Convenção para a Proteção do Patrimônio Mundial (UNESCO, 1972), em uma conjunção que enfraquece e deslegitima outras formas de identidade (SMITH, 2006; GNECCO, 2012). Segundo Gnecco e Ayala (2010), esta universalização e nacionalização do patrimônio transforma a história dos "outros" em "nossa" história. Além disso, por ser apenas uma entre muitas versões possíveis, não pode ser imposta sem violência simbólica - ou mesmo física -, tendo o apoio institucional e a conivência do Estado (GNECCO; AYALA, 2010, p. 23-24), o que caracteriza a tal "violência epistêmica" referida anteriormente.

Ora, em países onde o Estado tende a ser uma instituição de caráter assimilativo e integracionista, no qual os mais diversos grupos étnicos, religiosos e culturais são tanto passivamente como ativamente unificados numa só ideia nacionalista de povo e cultura, esta noção é obviamente problemática. A Convenção do Patrimônio Mundial é de fato bastante controversa, pois existe nela um enorme paradoxo: enquanto a UNESCO é uma organização apologista e defensora da "diversidade cultural", suas práticas são homogeneizantes (SCHRAMM, 2015, p. 445). Alvo de inúmeras críticas por parte de pesquisadores e culturas não ocidentais, a Convenção defende a existência de elementos arqueológicos, arquitetônicos e urbanos, assim como naturais, que por si próprios representam o engenho e criatividade humana e a diversidade natural e 
cultural do nosso planeta. Ora, como podem apenas alguns desses elementos representar tamanha diversidade? Esta questão nos remete para a forma como tais elementos são identificados, selecionados e nomeados através dos mecanismos da Convenção. Uma vez que ela atribui aos estados membros tais competências, consequentemente, estes tendem, de maneira invariável, a representar o carácter nacionalista e integracionista do próprio Estado. Essa problemática torna-se ainda maior quando nesses Estados existem grupos tradicionalmente marginalizados e violentados que não se veem representados numa ideia de patrimônio que geralmente apresenta valores colonialistas, elitistas e eurocêntricos (SMITH, 2006; HARRISON, 2010b). Vejam, por exemplo, que nos denominados países do Sul Global, apesar das mais variadas culturas indígenas, a grande maioria das inscrições na Lista do Patrimônio Mundial representa um passado colonial europeu - catedrais, centros históricos, fortalezas, edifícios ligados ao comércio de escravos. Mesmo quando valorizam culturas indígenas, a escolha recai sobretudo àquelas já extintas (ainda que isto não seja inteiramente verdade) e das quais restam apenas sítios arqueológicos monumentais que representam uma ideia ocidental de poder, civilização e progresso. Já os descendentes desses povos são obviamente ignorados ou desvalorizados. Por um lado, as civilizações pré-hispânicas são valorizadas como as raízes e orgulho da nação e, por outro, os seus descendentes são vítimas de todo o tipo de preconceitos e racismo e são tratados como cidadãos de segunda categoria ou estranhos nas suas próprias terras (JANSEN, 2006, p. 237).

A depreciação das culturas dos povos indígenas contemporâneos no discurso do Patrimônio Mundial está também ligada à falta de monumentalidade delas, o que revela um defeito de nascença da Convenção, qual seja, seu caráter eminentemente ocidental baseado numa ideia de patrimônio que privilegia o "monumento", a "obra de arte", o belo, o grandioso e o único (SMITH, 2006, p. 11 ). Mas, mais importante que uma definição de patrimônio, o que realmente está em causa aqui é a forma como ele interfere e traz consequências a amplos processos sociais, culturais, econômicos e políticos. De acordo com Smith (2006, p. 281), este discurso interpõe-se diretamente com a questão do controle sobre os significados e valores atribuídos ao passado e às ferramentas culturais usadas em processos de (re)criação de identidades e (re)interpretação de memórias. O patrimônio é, portanto, um ato político e uma demonstração de poder obviamente indissociável de conflito, uma vez que as relações estruturais entre, por exemplo, museus ou arqueólogos e povos indígenas se mantêm em grande parte relações coloniais. Logo, as relações de poder também não têm sofrido alterações. Uma vez que esta noção eurocêntrica de patrimônio exalta e fortalece uma determinada ideia de nação, a nomeação de elementos como patrimônio nacional ou mundial leva à sua desapropriação em favor do Estado, afetando os direitos de grupos "minoritários" que têm uma relação de pertencimento ou de identidade com esses elementos. Isto traz graves consequências sociopolíticas pelo fato de tal nomeação acarretar 
determinados direitos sobre os monumentos ou territórios, em termos de seus usos e exploração. No entanto, não podemos esquecer que 0 patrimônio forma a base de negócios relacionados ao turismo, geradores de milhões de euros de lucro. Como já referido por alguns pesquisadores (BERTACCHINI et al, 2016), o turismo e os negócios que lhe estão associados são também uma das principais motivações para a inclusão de elementos na Lista do Patrimônio Mundial, fato que pude atestar durante a minha participação no Fórum dos Jovens do Comitê da UNESCO em 2016.

Vários pesquisadores têm definido o patrimônio como um direito humano, e o seu acesso, gestão, proteção e valorização, como um processo diretamente relacionado com tal direito (GILBERT, 2010; MESKELL, 2010a; LOGAN, 2012). Uma vez que o patrimônio se entrecruza com o território no seu todo, isto é, com os seus elementos materiais e imateriais, este está diretamente relacionado e é inseparável da construção da identidade das comunidades e do acesso e controle dos lugares que lhes são relevantes para tal construção. Desagregar o patrimônio entre elementos materiais e imateriais reforça uma visão essencialmente dualista do mundo, onde se tratam fenômenos físicos e mentais como categorias ontologicamente distintas (HARRISON, 2015). Do ponto de vista dos Camëntsá, tanto os elementos físicos - lugares, edifícios - como os imateriais - rituais, festividades - merecem medidas de proteção e conservação integradas, pois são parte inseparável da sua cultura. Como os próprios referem, o Vale de Sibundoy é

- lugar onde nossa cultura é disseminada como povo indígena através dos nossos costumes, crenças, mitos, lendas, respiros, espiritualidades e convivência que nos permitiram manter vivos no espaço e no tempo (...). O sentido de pertencimento ao nosso território, o vínculo que temos com ele e as práticas que nele e em relação a ele exercemos, transpõem o território entendido como um mero espaço físico (...) o que necessariamente estabelece relações sociais e vínculos emocionais em outros planos e espaços. Esta é a base da nossa cultura (CABILDO CAMËNTSÁ, 2012, p. 30-31, tradução do autor).

Desta forma, é normal que tanto o controle de um território como a manutenção de uma identidade cultural própria sejam duas das principais reivindicações dos povos indígenas para obter a sua autodeterminação. O patrimônio torna-se, neste caso, não só um elemento fundamental no fortalecimento da identidade e coesão social, como também uma ferramenta a ser usada na luta contra processos de colonização. Entram assim em conflito duas noções de patrimônio distintas: uma que pretende representar a nação - e até toda a humanidade -, e outra que representa a construção de "localidade", isto é, de valores partilhados pela comunidade com base na sua relação com 
um determinado lugar, assim como a eventos e memórias coletivas a ele associados (HARRISON, 2010b). A exclusão sofrida por estas comunidades é ao mesmo tempo essencial para entender a forma como elas usam o seu patrimônio.

\section{Povos indígenas e os usos do patrimônio}

Inicialmente, convém esclarecer que o patrimônio não é uma "coisa", mas um processo (SMITH, 2006) que, por sua vez, não pode ser reduzido a uma trajetória unilinear, pois não existe um patrimônio que seja universal. Qualquer elemento estará sempre sujeito à interpretação que diferentes grupos lhe outorguem, gerando conflitos irresolúveis (SCHRAMM, 2015, p. 442). Por esta razão, prefiro gestão à conservação do patrimônio. No mesmo sentido, alguns pesquisadores têm sugerido que falemos em patrimônios (ASHWORTH et al., 2007 apud SCHRAMM, 2015). É precisamente este componente que mais me interessa: o significado do patrimônio para aqueles que não têm sido ouvidos - tanto pelos Estados como pela academia -, dando-lhes voz e representando saberes contra-hegemônicos (BAPTISTA DA SILVA, 2017) e práticas de resistência dos povos indígenas através do uso do patrimônio.

O uso do patrimônio como forma de persuasão tem sido referido por vários pesquisadores (SAMUELS; RICO, 2015). No caso dos povos indígenas, esta ação está geralmente relacionada com a obtenção de autonomia política, territórios ancestrais, segurança alimentar e uma identidade cultural própria. O patrimônio é usado neste contexto como modo de demonstrar, por exemplo, como uma comunidade está enraizada em um território do qual se viu desapropriada, exaltando uma forma própria de pensar e agir para com a sociedade ou uma maneira sustentável de viver em harmonia com a natureza, de modo a continuar uma longa luta contra agentes externos colonizadores e predadores dos seus territórios (MARQUES MIRANDA, 2016). Focando-nos no caso do povo Camëntsá, podemos ver que determinados elementos patrimoniais costumam ser usados com este intuito. As tradicionais máscaras esculpidas em madeira, como as dos sanjuanes, são interpretadas como símbolos da dor causada pela opressão sofrida durante os últimos séculos. O ritual da degolação do galo praticado durante o Bëtscnaté também é interpretado como um gesto de escárnio no qual o referido animal, representando a Igreja, é degolado, por um dos membros da comunidade indígena com a finalidade de exprimira manutenção da integridade cultural e o fortalecimento dos valores de seu povo apesar da forte influência das distintas missões evangelizadoras presentes no território camëntsá desde a conquista espanhola (IGLESIAS ALVIS, 2008). A inclusão de estátuas no Parque da Interculturalidade simboliza a cosmovisão camëntsá - embora essas estátuas à primeira vista passem despercebidas, dada a monumentalidade da catedral e da cruz - ao também representar a resistência deste povo, além de enfatizar a 
importância da reivindicação deste território perante o Estado enquanto parte constitutiva da identidade desta sociedade. Não é por acaso que estes elementos e espaços são utilizados na celebração mais importante deste povo, o Bëtscnaté.

De acordo com Hafstein (2012, apud SAMUELS; RICO, 2015, p. 67), o principal uso do patrimônio é mobilizar pessoas e recursos, reformar discursos e transformar práticas, tendo mais relevância as alterações sociais que causa do que a conservação per se do patrimônio, pois, como afirma Samuels, "o passado é mobilizado no presente: tornase um ponto de vista, uma performance, [...] ou uma narrativa rival para realizar movimentos estratégicos em lutas mais amplas" (SAMUELS; RICO, 2015 , p. 7, tradução do autor). Objetos, lugares e práticas patrimoniais são usados localmente para construir ou fortalecer um sentido de identidade e de comunidade, com o objetivo de obter legitimidade e gerar mudanças sociais positivas, indo de encontro à maneira como o patrimônio é entendido e usado pelo Estado em um sentido top-down (HARRISON, 2010a). O uso de práticas imateriais associadas a outras formas materiais é entendido como um processo essencial para manter a conexão das comunidades com um determinado espaço e entre elas mesmas. Projetos de conservação do patrimônio requerem união e trabalho comunitário, assim como a partilha de determinados valores. A título de exemplo, não é propriamente a preservação física deum edifício que é relevante, senão a performance, o processo constante de valorizálo para, assim, reinterpretar e recriar uma identidade e uma comunidade (SMITH, 2006; KARLSTRÖM, 2009).

O desrespeito a que os povos indígenas são submetidos, inclusive no âmbito de projetos de conservação e gestão do patrimônio endossados por organismos como a UNESCO, tem sido alvo de duras críticas e reprovação, pois tais projetos não têm levado em conta as comunidades que vivem em lugares declarados patrimônio mundial (IWGIA; FPP, 2015), lugares dos quais estas comunidades dependem para levar uma vida segura. Torna-se fundamental, portanto, que estes projetos sejam realizados com consentimento, consulta e informação prévios das comunidades, além da participação ativa destas na determinação da forma como os elementos patrimoniais devem ser geridos e conservados. De forma bastante perversa, o discurso do Patrimônio Mundial - e os seus derivados a nível nacional - costuma ser aplicado com o intuito de excluir as próprias comunidades dos seus territórios, como no caso dos povos indígenas no noroeste da Tailândia (MARQUES MIRANDA, 2016), das populações dos Parques Nacionais de Simien na Etiópia, Ukhahlamba-Drakensberg (MAUREL, 2017) e Kruger na África do Sul (MESKELL, 2005), entre outros. Ancorado na justificativa de proteger e conservar um patrimônio que é de todos, os Estados possuem o objetivo de se apropriar dos territórios de uma forma que parece legítima. Também é problemática a tentativa de obter o controle de territórios pertencentes a outros Estados soberanos, como no caso da 
disputa entre a Tailândia e o Camboja pelo templo de Preah Vihear. Como afirma Logan (2012, p. 239), algumas tentativas de proteger o patrimônio têm, paradoxalmente, representado ameaças a outros direitos humanos. Projetos que põem em causa os direitos humanos e coletivos de comunidades indígenas deveriam estar no topo das preocupações de uma organização que tem como princípios fundamentais a paz e a segurança a nível mundial. Promover a diversidade cultural e simultaneamente patrocinar a integração e consequente destruição de culturas indígenas e desfavorecidas no seio dos estados membros é um dos contrassensos mais fortes na ideia de Patrimônio Mundial, que faz com que esta perca legitimidade e aceitação por parte dos povos indígenas. Numa lógica ocidental em que o patrimônio é controlado por quem detém o poder, sobra aos Camëntsá socializar o seu patrimônio em um sentido bottomup, tornando-o um ato evidentemente político. A (re)criação de uma identidade própria e o seu fortalecimento, no sentido de se diferenciar do outro, é um assunto bastante sensível às comunidades colonizadas e marginalizadas, pois procurar a legitimação da sua cultura pode ser encarado como um ato de rebelião contra o Estado. Ironicamente, o patrimônio pode tanto ser usado para excluir minorias da narrativa nacional quanto ser visto como uma tentativa, por parte destas, de enfraquecer a soberania do Estado (HARRISON, 2010b). No entanto, este discurso alternativo empregado pelos Camëntsá não é um discurso de isolamento ou aversão face à cultura ocidental, mas sim um apelo ao respeito à sua própria cultura e à sua maneira de ver o mundo, para que o seu território ancestral seja reconhecido e a sua forma sustentável de se relacionar com a natureza seja valorizada. Igualmente, o modo como os Camëntsá relacionam-se entre si, evidenciado no Bëtscnaté, assim como na sua abertura a todos os forasteiros, demonstra uma cultura de paz, harmonia e reconciliação, tão necessária quando dois mundos contrastantes se chocam.

Os rituais realizados em Uaman Tabanoc denotam que o significado atribuído a este lugar pelos Camëntsá desafia o significado nacionalista, no qual a localidade - fundada por conquistadores e evangelizadores espanhóis - e o parque central - que agora conta com a sede do município, escolas, a catedral e uma grande cruz como principais pontos de referência - representam a autoridade estatal e a fé cristã. No que diz respeito à história oficial, a existência e a relação ancestral do povo Camëntsá com esta região é completamente ignorada. Os Camëntsá veem a declaração do parque central de Sibundoy como seu lugar sagrado enquanto um importante ato para recuperar a sua identidade, fortalecer a memória coletiva e reforçar a coesão social, funcionando como um elemento persuasivo na luta pela justiça social. No entanto, Lamentacionënts carece de monumentalidade - a catedral não é considerada parte da cultura camëntsá - e, com respeito aos rituais realizados, sua declaração como Patrimônio Cultural Imaterial não viabiliza o pleno acesso e gestão do lugar de acordo com a cosmovisão e cultura camëntsá. O conceito de patrimônio imaterial tornou-se um 
elemento dominante no discurso acadêmico e das políticas culturais nacionais e internacionais nas últimas décadas. De fato, uma das razões que justificam a criação da Convenção para a Salvaguarda do Patrimônio Cultural Imaterial (UNESCO, 2003) é precisamente a de representar comunidades marginalizadas e outros conceitos de patrimônio (SCHRAMM, 2015; RODRIGUEZ URIBE; RODRIGUEZ URIBE, 2013) ou, como refere Gnecco de uma forma mais crítica, uma prática para sujeitar os "recém-chegados das margens" a instrumentos de governabilidade (2015, p.272). Além disso, esta noção de patrimônio imaterial cria uma divisão artificial que debilita a reciprocidade dos elementos tangíveis e intangíveis da vida cotidiana (ICOMOS, 2014). Um exemplo deste problema pode ser evidenciado na declaração do Bëtscnaté como Patrimônio Imaterial da Nação em 2013. Embora a interdependência entre ritual e lugar seja reconhecida, através dos mecanismos do Ministério de Cultura da Colômbia (2010, p. 244-5 e 249) ou da Convenção para a Salvaguarda do Patrimônio Cultural Imaterial (UNESCO, 2003, artigo 2, parágrafo 1), declarar como patrimônio imaterial uma celebração com tal complexidade é ineficaz e insuficiente para que esta seja salvaguardada. Especificamente a celebração, mas também a cultura Camëntsá em geral, depende fortemente dos valores e significados espirituais e históricos atribuídos ao parque central da vila, existindo assim uma necessidade fulcral de salvaguardar em conjunto os significados, valores e o espaço físico. Ao separar o patrimônio entre elementos materiais e imateriais estamos desprezando a relação entre pessoas e lugares e rejeitando a ideia de que o acesso físico a um lugar culturalmente importante é um aspecto essencial na gestão do patrimônio (ARMSTRONG-FUMERO; HOIL GUTIERREZ, 2017). O plano de salvaguarda do Bëtscnaté (MINISTERIO DE CULTURA, S/D) não só impõe conceitos que são alheios aos Camëntsá como é totalmente surreal para que estes o levem a cabo, uma vez que baseado na construção de infraestrutura, está demasiadamente focalizado na preservação física do patrimônio. Além disso, outro fator igualmente problemático diz respeito à necessidade de que os Camëntsá se candidatem a fundos para desenvolver estes projetos de salvaguarda que, por sua vez, requerem o conhecimento de profissionais externos. Impõe-se, assim, a típica prática ocidental de identificar, tirar medidas, descrever materiais, catalogar e arquivar mesmo quando se refere explicitamente à necessidade de viver e experienciar o patrimônio para este ser salvaguardado. De forma geral, através destes mecanismos os povos indígenas têm de se adaptar a conceitos ocidentais - com a posição privilegiada de seu discurso universalista -, através da figura dos especialistas, para decidir como o patrimônio deve ser gerido (KARLSTRÖM, 2009, p. 213; HAFSTEIN, 2014).

No que diz respeito ao museu de Sibundoy, esta problemática se mantém. A comunidade está extremamente interessada em ter o seu próprio espaço, onde os seus objetos possam ser exibidos e seus valores e narrativas associadas transmitidos de acordo com a perspectiva camëntsá - incluindo o conhecimento particular desta sociedade acerca 
do território e sua conservação. No entanto, o museu reflete a ideia de que a cultura camëntsá ficou estagnada no passado e se foca exclusivamente nos seus aspectos materiais. Os objetos são exibidos sem que os seus significados e funções sejam mencionados, encontrando-se pendurados nas paredes e dentro das vitrines como memórias intocáveis de um passado distante, enquanto para os Camëntsá os objetos devem ser tocados e usados, sua função e significado recuperados e recontados e as memórias a eles associadas, revividas. Contudo, a perspectiva acerca da cultura indígena local evidenciada no museu de Sibundoy vai ao ponto de manter uma percepção colonialista ao catalogar objetos camëntsá como "pré-colombianos". Gnecco e Ayala (2010, p. 30) assinalam que esta ruptura da continuidade histórica foi uma das estratégias que o colonialismo usou para transformar as histórias locais e impor um novo sentido de tempo. Não esqueçamos também o papel fundamental da Igreja neste processo de desvalorização e extirpação da relação dos povos indígenas com os seus antepassados (p. 30-31), que paulatinamente os foi transformando em povos sem história (JANSEN, 2006, p. 248).

Figura 3 - Museu de Sibundoy.

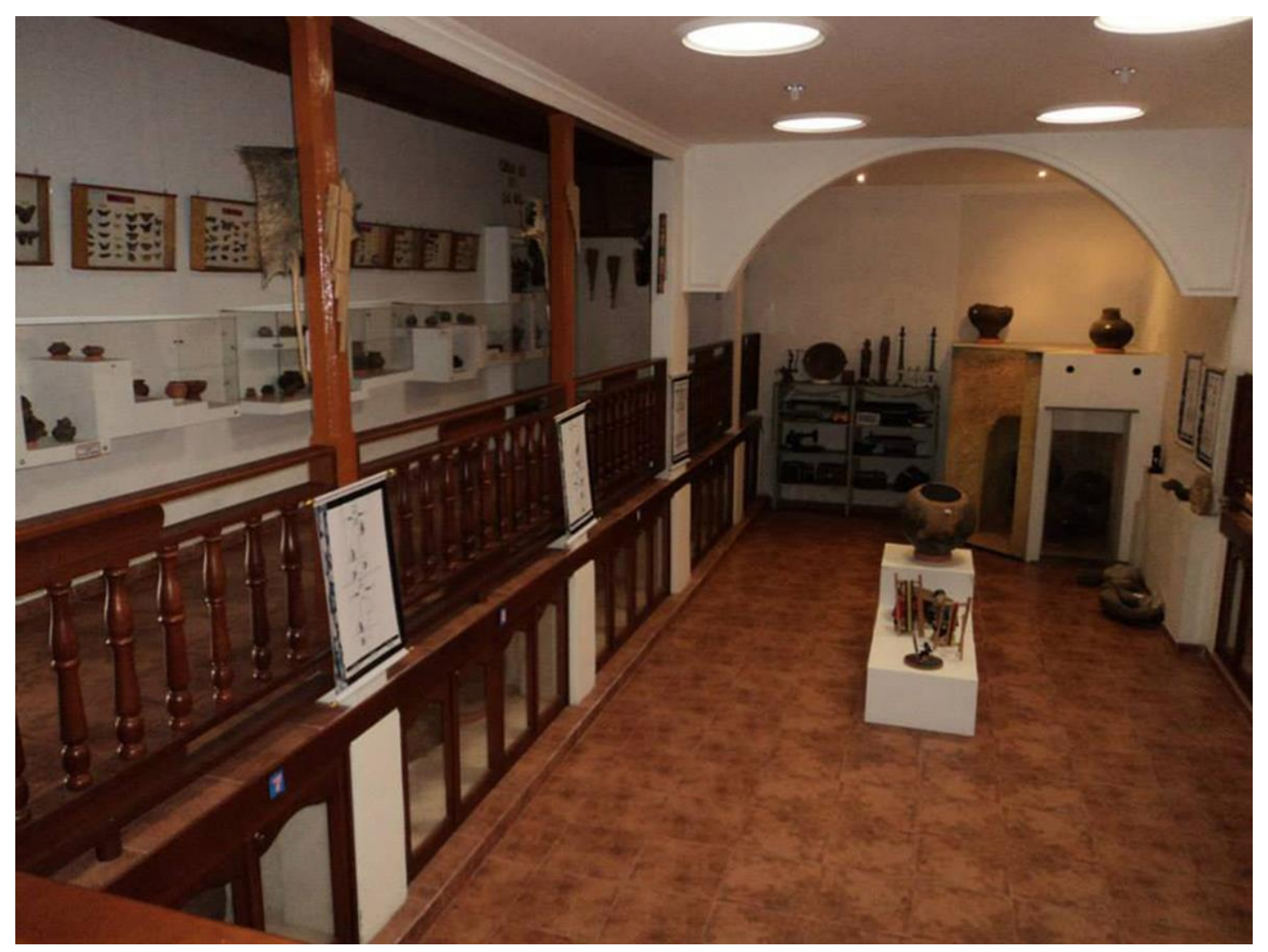

Fonte: Jully Acuña. 2017. 
Esta abordagem não reconhece os interesses da comunidade e o fato de que esta tem o direito a possuir relações particulares com o passado intelectual e material, negligenciando completamente, portanto, a existência de práticas locais e tradicionais para cuidar de objetos práticas que poderiam armar as bases para formas culturalmente apropriadas de gestão do patrimônio (HOLLOWELL; NICHOLAS, 2009), mas que ao não serem integradas transforma as comunidades em receptores passivos de conhecimento ao invés de praticantes, já que apenas os especialistas externos têm o direito e o conhecimento para usar e cuidar do patrimônio, além da capacidade de educar adequadamente o público. Esta abordagem restrita omite uma série de outras experiências sociais e culturais, e não é por acaso que tais abordagens têm sido criticadas por excluir as comunidades indígenas e outros grupos desfavorecidos (SMITH, 2006). Fica evidente também, sem surpresa alguma, que não houve qualquer tipo de envolvimento, consulta ou consentimento do povo Camëntsá ao se criar um museu que exibe a sua cultura.

Figura 4 - Casa tradicional, a única existente atualmente, no Lar de Crianças Basetemëngbe Yebna

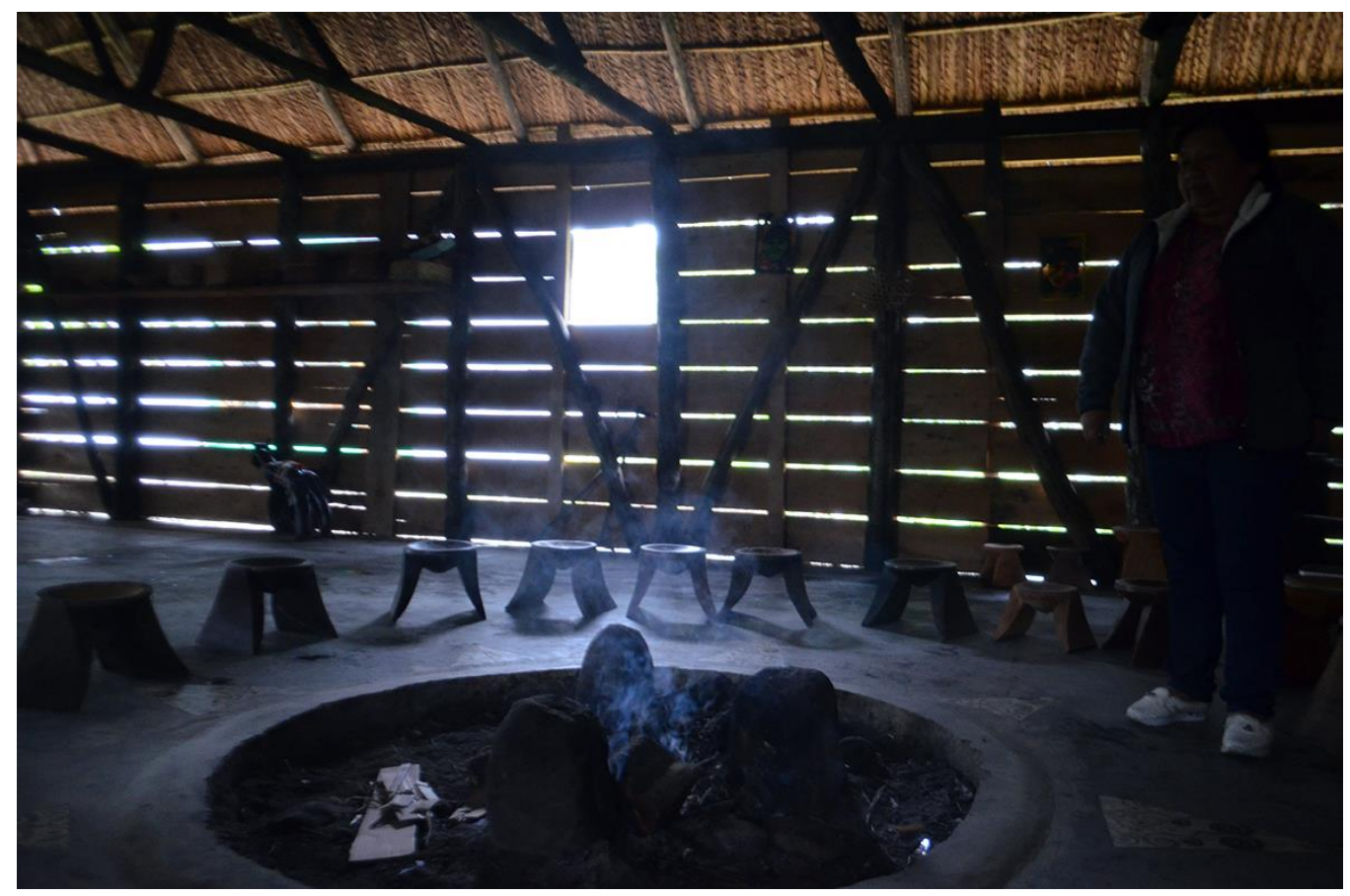

Note-se a presença da lareira (shin̈̈ac) com três pedras que representam o pai, a mãe e os filhos. Fonte: Jully Acuña. 2017. 
Existem vários espaços camëntsá para a transmissão do conhecimento que podem ser adaptados e incorporados à prática museológica. Elementos como o shinÿac (lareira) o jajañ (práticas agrícolas tradicionais) ou o enaboatëmbayán (forma tradicional de trabalho comunitário) são espaços onde a sabedoria e a espiritualidade dos anciãos e o conhecimento sobre a natureza são transmitidos, onde valores são identificados e conselhos são dados, onde as gerações mais jovens aprendem a se comportar e a trabalhar em comunidade (CABILDO CAMËNTSÁ, 2012). Para além disso, a comunidade tem as suas próprias noções sobre como os objetos devem ser exibidos e as suas histórias contadas. Tal trabalho não deve ser dirigido por um especialista externo, mas em colaboração com os verdadeiros especialistas acerca da cultura camëntsá: os anciãos e autoridades indígenas tradicionais.

Porém, como na maioria dos casos, o museu trata o patrimônio como uma criança indefesa, a quem devemos proteger e guardar, e o despoja de seu sentido histórico (GNECCO, 2012, p. 53). Consequentemente, é natural que os anciãos e as autoridades camëntsá expressem a preocupação de que "hoje em dia, os jovens indígenas, em particular, estão se tornando observadores do patrimônio cultural e não seus atores e praticantes" (CABILDO CAMËNTSÁ, 2012, p. 172, tradução do autor).

Quando olhamos para as diferenças nos princípios éticos do patrimônio entre o discurso estatal e da comunidade indígena vemos que este se torna dissonante. Enquanto o primeiro se compromete a proteger o patrimônio para benefício de todos, o segundo procura preservar e proteger as relações entre os vivos e os antepassados para seu próprio benefício (HOLLOWELL; NICHOLAS, 2009). Diferentes narrativas e interpretações do mesmo lugar por parte de vários grupos que reivindicam o seu controle e "propriedade" invariavelmente geram contestação e conflito. Tal dissonância só poderá ser apaziguada se as diferentes narrativas forem reconhecidas e outras interpretações do passado forem acolhidas (SINGH 2008). Este esforço exige uma abordagem mais holística e inclusiva na gestão e conservação do patrimônio, respeitando, em primeiro lugar, as cosmovisões, os territórios e as concepções de "bem viver" dos povos indígenas (GILBERT, 2010). No entanto, os mecanismos de gestão do patrimônio na Colômbia não abordam ainda estes aspectos.

\section{Perspectiva intercultural na gestão do patrimônio e os potenciais da etnografia arqueológica}

O Projeto Bëngbe Benacheng visa a entender a interpretação local de patrimônio com base numa abordagem "descolonizadora", levando em consideração as relações intergovernamentais e as responsabilidades 
destas instituições, assim como a questionar as políticas culturais do Ministério de Cultura e da UNESCO, com o objetivo de propor a reconceitualização de patrimônio e a produção de mecanismos de proteção para que os Camëntsá - e, por conseguinte, outros povos indígenas - possam ser incluídos no processo. O modo como estes conceitos camëntsá podem se articular com políticas e legislação de patrimônio é algo que precisa ser discutido e negociado entre a comunidade e essas instituições. Tal articulação colocará os Camëntsá numa posição muito mais forte para tomar decisões informadas sobre como implementar suas próprias políticas de gestão patrimonial. No entanto, os mecanismos existentes em tais instituições dificilmente são compatíveis com os do povo Camëntsá. Por esse motivo defendo que a investigação+ação colaborativa e intercultural baseada em princípios camëntsá de gestão do patrimônio, com um forte componente etnográfico, é uma maneira apropriada, respeitosa e potencialmente emancipadora para levar a cabo este esforço.

Reconceitualizar o patrimônio significa entender este como um processo cultural, isto é, que objetos e lugares não têm um valor patrimonial inerente, mas é o seu uso e o que acontece nesses sítios que Ihes outorga tal valor (SMITH, 2006, p. 44). Consequentemente, 0 patrimônio não pode ser definido como um "bem" ou "propriedade" de um grupo específico, pois isso significaria que seu uso ou acesso por parte de outros grupos - com diferentes interpretações - seria recusado. Usando o caso dos Camëntsá como exemplo, podemos verificar que são as práticas relacionadas com ou que fazem uso de objetos e lugares que são consideradas patrimônio e, como dito anteriormente, a sua preservação física pode não ser necessária. O patrimônio reside nos atos de relembrar, recriar e reviver ou experienciar os valores e significados que tais objetos e lugares transmitem. Quando refiro que a preservação física de um lugar pode não ser necessária, chamo a atenção para a preservação de elementos tradicionalmente reconhecidos como patrimoniais - tal como objetos de arte ou edifícios históricos - que fazem parte desse lugar. Tomando Lamentacionënts como exemplo, podemos entender que a conservação das atuais estátuas camëntsá, do mobiliário urbano ou da cruz central, que poderiam ser vistos como elementos artísticos ou históricos, é secundária ou mesmo irrelevante. De fato, muitas vezes é mais relevante que estes elementos, quando deteriorados, sejam substituídos por elementos novos, pois o processo de constante recriação artística é visto como um modo de manutenção da cultura viva. No entanto, isso não significa que a total destruição do parque seja aceitável. O importante é que os Camëntsá possam ter acesso a este para levar a cabo as práticas culturais a ele associadas, e que estas sejam respeitadas pelos outros grupos que habitam o vale. O conceito de "apego ao lugar" (KOSTANSKI; CLARK, 2009, p. 197), ou seja, a forma como a comunidade atribui significado a um espaço físico através da interação com ele - gerando assim uma conexão identitária e cultural -, é fundamental para entender esta relação. Tal como no caso do povo 
Muruwari (HARRISON, 2010a, p. 256), este lugar atua para os Camëntsá como um ponto essencial na interação entre o passado e o presente, bem como entre os mundos vivo e espiritual. Através da conexão que cria com o passado, Lamentacionënts é um memorial autêntico com o qual criativamente se constrói uma nova memória coletiva. Outro exemplo essencial para abordar o patrimônio nesta perspectiva é a forma como os Camëntsá se relacionam com o território no seu todo. Não um território concebido como propriedade e materialidade com limites geometricamente definidos, mas enquanto conexão entre planos físicos e planos emocionais, espirituais e culturais (CARDOSO et al., 2017, p. 75). Para tanto é necessário um ato constante de reconhecimento deste território, a que os Camëntsá se referem ao "percorrer os caminhos dos antepassados", renovando e respeitando assim a relação com Tsabatsána Mamá (CABILDO CAMËNTSÁ, 2012). Para povos indígenas como os Camëntsá, o território é sinônimo de patrimônio e, assim como tal, deve ser abordado de uma forma holística e não como portador de elementos separados com base nas suas propriedades tangíveis ou intangíveis.

Figura 5 - Caminhada para reconhecimento do território, dirigida sobretudo às gerações mais jovens.

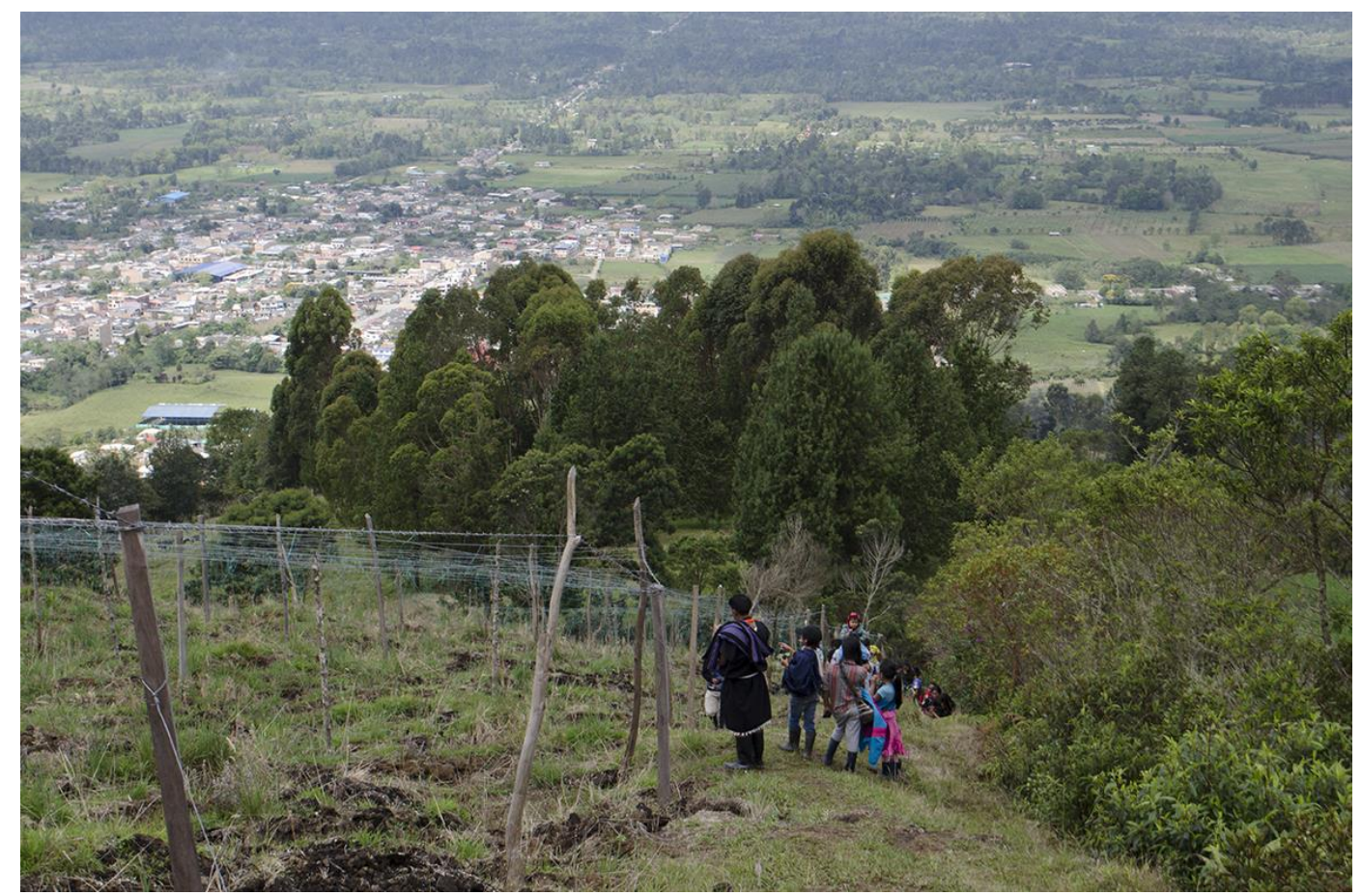

Fonte: Jully Acuña. 2017. 
A perspectiva intercultural do Projeto Bëngbe Benacheng diz respeito ao cruzamento de disciplinas, bem como de fronteiras culturais e sociais, étnicas, nacionais, de classe, de gênero ou de idade. Envolve negociar os significados e aceitar se abrir a novas possibilidades, criando empatia entre os diferentes grupos envolvidos (RAFFA, 2015). Neste contexto, torna-se também particularmente importante o uso da língua camëntsá na definição e nomeação de elementos do projeto. Como refere Jansen (2006, p. 242), os pesquisadores devem conhecer o idioma nativo pois nele se formulam nomes, conceitos, convicções e sentimentos que de outra maneira não se podem compreender. Também as formas e funções da cultura material estão refletidas e classificadas no idioma nativo. Consequentemente, a pesquisa deve ser combinada com a história oral e a paisagem através de um compromisso participativo sério com a comunidade indígena. Uma abordagem intercultural da proteção e gestão do patrimônio implica entender este processo como um trabalho social contínuo e reconhecer as dimensões sociais e culturais das relações das comunidades com os seus lugares, objetos e territórios. Envolve entender a proteção e gestão do patrimônio como um processo mais complexo do que a simples preservação dos seus elementos materiais, pois este está diretamente relacionado com cosmovisões locais, religiões, experiências e memórias coletivas que devem ser respeitadas. Trata-se também de cultivar relacionamentos harmoniosos dirigidos a reparar injustiças históricas. Pretende-se, assim, dar voz e visibilidade àqueles que têm sido esquecidos e negligenciados. Para tanto, é fundamental que se partilhe a autoridade durante todo o processo, dando espaço à inclusão de múltiplas formas de conhecimento (KREPS, 2006). O trabalho levado a cabo em conjunto com as autoridades, com a comunidade indígena e com outros grupos é essencial para que os diferentes interesses não se sobreponham e constitui um pré-requisito para fomentar o diálogo e a compreensão entre as culturas envolvidas. Trabalhar em conjunto não pode voltar a implicar em usar os povos indígenas como se estes fossem apenas um conjunto de voluntários, consultores, ou objetos de estudo. Significa estabelecer um compromisso com as comunidades em uma série de níveis. Além disso, necessitamos passar a considerar questões do interesse destes grupos. Consultar uma comunidade indígena na criação de um museu ou de um plano de conservação/salvaguarda só será verdadeiramente respeitoso e eficaz quando a perspectiva da comunidade for realmente incluída e estes beneficiem a comunidade.

Nos parágrafos seguintes, exemplificarei o marco teórico e a metodologia do Projeto Bëngbe Benacheng com referência a um dos pontos que o projeto se focaliza - denominado "registro arqueológico" - e os lugares sagrados do povo Camëntsá.

Uma abordagem colaborativa e intercultural implica então uma visão mais abrangente e integrada do patrimônio, eliminando as tradicionais dicotomias existentes no conceito ocidental (material/imaterial, natural/cultural, especialistas/comunidades, 
conhecimento científico/tradicional, custódia/propriedade, passado/presente, local/nacional). Dentro deste processo cabe também reconhecer, conservar e promover modelos tradicionais de gestão do patrimônio, uma vez que estes não só têm valor em si mesmos como expressões culturais únicas e como exemplos de diversidade cultural, como também contribuem para a nossa compreensão de como as comunidades em diferentes contextos culturais interpretam, valorizam, protegem e preservam as suas culturas, demonstrando que não há um patrimônio universal (KREPS, 2006). Esta perspectiva crítica está direcionada à elaboração de perguntas incômodas sobre as formas ocidentais de pensar o patrimônio e a trazer os interesses de grupos marginalizados e excluídos a um primeiro plano, reduzindo as desigualdades de poder evidenciadas nos tradicionais processos topdown de gestão do patrimônio, e revolucionando a maneira como este é entendido por órgãos governamentais, acadêmicos e o público em geral. O patrimônio deve ser relacionado com os desafios críticos do nosso tempo, incluindo mudanças climáticas, conflitos armados, descolonização, migração, mudanças econômicas globais ou justiça transicional, reconhecendo, sobretudo, que este tem a capacidade de funcionar positivamente como facilitador na resolução de tais desafios (WINTER, 2013). Os modelos de investigação direcionados somente à ciência devem ser redirecionados e desenvolvidos para que as comunidades estejam envolvidas como colaboradores da pesquisa. Os estudos do patrimônio devem estar enraizados na comunidade e no local de forma a fornecerem uma perspectiva fundamental sobre o impacto das políticas do patrimônio e projetos de gestão e conservação. Ademais, os resultados da pesquisa devem ser aplicados para que se mudem os processos e desigualdades resultantes dessas abordagens (SCHENSUL et al., 2015). Em resumo, podemos denominar de forma geral esta abordagem como uma "pesquisa transformacional" (SCHENSUL et al., 2015), nos referindo a uma forma de estudo aplicado que aborda questões de desigualdade nas comunidades, geradas através da distribuição desigual de recursos políticos, econômicos, sociais, etc. Por transformação entendemos a capacidade de gerar mudanças sociais para equilibrar as relações de poder e melhorar o acesso a recursos.

Para tanto, a metodologia a ser utilizada nesta pesquisa é a etnografia arqueológica. Este método está conformado por um conjunto de práticas tradicionais em arqueologia e museologia, combinado com métodos artísticos inovadores e métodos etnográficos tradicionais. Como os arqueólogos não devem limitar o seu estudo ao passado material (WOBST, 2010, p. 17), a etnografia arqueológica busca explorar a relevância e significado contemporâneo que o passado material tem para diferentes públicos, as políticas da prática arqueológica e as reivindicações e contestações que dizem respeito ao passado material de vários períodos, envolvendo, para isso, vários investigadores e participantes, e contribuindo, assim, para a descolonização da prática acadêmica. Não se trata de uma simples prática resultante da combinação 
entre a arqueologia e a antropologia, mas de um espaço transdisciplinar, intercultural e com carga política onde têm lugar múltiplas conversações, confrontações, intervenções e críticas, centrado na materialidade e temporalidade (HAMILAKIS; ANAGNOSTOPOULOS, 2009). O surgimento deste espaço requer que a arqueologia "oficial" seja contestada, o que significa mais do que a reintrodução de métodos etnográficos na prática arqueológica - a que poderíamos nos referir como etnoarqueologia -, pois procura desafiar as certezas da arqueologia e a crença na sua autoridade absoluta, assim como sua naturalização pelos seus praticantes como o único e exclusivo agente responsável pela produção de discursos e práticas sobre o passado material (p. 66). Não é por acaso que uma das razões para o seu surgimento seja o confronto à autoridade da arqueologia por parte de povos indígenas e outros grupos desfavorecidos. A arqueologia é, assim, vista como apenas uma entre as muitas formas possíveis de obter conhecimento, reconhecendo que os povos indígenas têm as suas próprias e legítimas versões do passado e que os arqueólogos dependem muito mais destes para o compreender do que o contrário. Neste sentido, queremos que a arqueologia conte uma história com significado e valor para o povo Camëntsá, explorando a continuidade cultural refletida na cosmovisão indígena, de forma a evitar a destruição da memória histórica (JANSEN, 2006). A etnografia arqueológica fornece uma maneira de entender os discursos de patrimônio "não oficiais" e como a identidade cultural das comunidades é baseada e moldada através do registro arqueológico. Além disso, as comunidades locais não são meros agentes passivos da pesquisa, mas estão diretamente envolvidas na construção de conhecimento e interpretação, reformulação crítica e negociação política (HAMILAKIS \& ANAGNOSTOPOULOS, 2009). A etnografia arqueológica implica colaborar com as pessoas ao invés de estudá-las (MESKELL, 2010b, p. 449), isto é, incluir na equipe de pesquisa aqueles que normalmente são apenas tidos em conta como "informantes" (HAMILAKIS; ANAGNOSTOPOULOS, 2009, p. 82). Ao contrário do que acontece numa arqueologia com uma perspectiva evolucionista - que dá relevância à escavação estratigráfica -, aqui é a interação, conversação, e a colaboração com as pessoas que se transforma no principal método de pesquisa (JANSEN, 2006, p. 241). Resumindo, em detrimento de falar de ou para, o projeto procura dialogar com o povo Camëntsá. Este foco em aspectos imateriais é também fundamental para ir mais além do fetichismo de objetos característico das disciplinas que lidam com o patrimônio (JANSEN, 2006; GNECCO; AYALA, 2010).

De acordo com Harris (2010) existem quatro áreas nas quais o conhecimento indígena pode contribuir para a arqueologia: 1) a história oral, como fonte de informação para orientar a pesquisa e interpretar dados; 2) a toponímia, uma vez que esta fornece informação acerca das definições, usos e eventos ocorridos na paisagem; 3) a mnemónica dos objetos, pois estes não são apenas objetos de arte, mas contam suas próprias histórias sobre lugares ou eventos passados; 4) o território, 
imbuído de histórias e não simplesmente como espaço físico. Por outro lado, a arqueologia tem o dever de dignificar, proteger e trazer benefícios às comunidades com as quais trabalha (JANSEN, 2006, p. 247-249). Lilley e Williams (apud MESKELL; PREUCEL, 2004, p. 323) esboçam um conjunto útil de imperativos que são incorporados neste projeto: 1) deve ser reconhecido que os povos indígenas têm um conjunto diferente de interesses legítimos pelo registro arqueológico; 2) aceitar que questões e aproximações, de um lado, não deve dominar ou enfraquecer as do outro; 3) definir áreas de interesse mútuo que podem realçar objetivos arqueológicos e não arqueológicos e preencher a lacuna entre grupos interessados. Ademais, este projeto tem em conta seis níveis práticos de envolvimento (MESKELL; PREUCEL, 2004, p. 327) com a comunidade: 1) reconhecimento da prévia propriedade das terras por parte da comunidade indígena; 2) consulta prévia e constante com a comunidade; 3) apresentação útil do trabalho de campo à comunidade; 4) emprego e formação entre a comunidade; 5) proteção de sítios sagrados; 6) permitir interpretações variáveis entre profissionais, acadêmicos e indígenas.

A necessidade de um método como a etnografia arqueológica se baseia no fato de os estudos do patrimônio - em particular os relacionados com a arqueologia e a museologia - ainda refletirem remanescentes do colonialismo, paternalismo e racismo (MESKELL, $2010 b)$ que são evidentes, por exemplo, no museu de Sibundoy. Afinal de contas, estas disciplinas se desenvolveram em conexão com a noção de Estado e as ideologias nacionalistas (JANSEN, 2006, p. 240), o que levou à falta de consideração pelos interesses das comunidades locais indígenas ou não - prevalecendo os interesses dos arqueólogos (GNECCO; AYALA, 2010, p. 38) que, por seu lado, não podem ignorar seu papel na construção de discursos colonialistas e a cumplicidade entre a disciplina e o colonialismo (p. 28, 42). Uma vez que a etnografia tem servido, sobretudo, para promover os objetivos da arqueologia, o projeto promove o uso emancipatório da etnografia pela comunidade de maneira a oferecer formas de empoderamento ao articular as suas próprias leis e conceitos de patrimônio e sua gestão. Desta maneira, mudamos o foco do que a etnografia pode fazer pela arqueologia "oficial" para uma "etnografia da arqueologia" que, por sua vez, altera uma gestão do patrimônio que trabalha para servir aos interesses da arqueologia de modo a colocá-la nas mãos das comunidades indígenas (HOLLOWELL; NICHOLAS, 2009). As comunidades têm, assim, a oportunidade de desenvolver as suas próprias práticas e conceitos de gestão do patrimônio e as entrelaçar com as do sistema dominante, de a maneira a efetuar mudanças sociopolíticas.

Ao dialogar com membros da comunidade Camëntsá sobre sítios, objetos e restos humanos, muitas vezes ouvi as expressões "o que você define como arqueologia" ou "o que você refere como artefatos arqueológicos". Neste caso, como em muitos outros (ALLEN; PHILLIPS, 2011), os Camëntsá valorizam mais as qualidades espirituais, 
experienciais e intangíveis desses elementos do que as materiais, científicas e artísticas. Embora o que a arqueologia lhes possa dizer sobre seu passado é bem-vindo e importante, não se pode ignorar que a manutenção desses valores é essencial. Aceitar métodos indígenas para criar e preservar o conhecimento, bem como combinar estes com o conhecimento adquirido através de métodos científicos, leva à expansão dos horizontes das disciplinas que estudam o fenômeno do patrimônio. As possibilidades de tal cooperação demonstradas por vários projetos (GNECCO; AYALA, 2010; MENDIZÁBAL; THEODOSSOPOULOS, 2012; DANSAC, 2015; JANSEN; RAFFA, 2015; MAY CASTILLO; STRECKER, 2017) demonstram como estes podem produzir uma arqueologia e museologia muito mais ricas e incentivar investigações de patrimônio numa região onde tais ações são desesperadamente necessárias, bem como descolonizar a representação dos povos indígenas nas disciplinas. Estes casos demonstram muitas semelhanças com o caso do povo Camëntsá e Sibundoy e fornecem evidências adicionais de tal colaboração entre acadêmicos e comunidades indígenas, especialmente como os primeiros são orientados pela experiência indígena e conhecimento do meio ambiente e paisagem local. Estas comunidades mostram um enorme interesse em articular suas próprias noções de patrimônio e identidade e de revelar as suas narrativas através dos restos materiais do passado, deixadas de lado por narrativas oficiais e nacionalistas. Como afirmam Gnecco e Ayala (2010, p. 42), uma arqueologia relacional é uma arqueologia que está aberta a outras visões, narrativas e mundos, e que levará à transformação da disciplina e da sua forma de se engajar com as comunidades assim como de se comprometer com a luta por um mundo mais justo.

O projeto Bëngbe Benacheng é uma colaboração com a comunidade para entender e preservar o seu patrimônio e defender seus direitos sobre ele através da pesquisa colaborativa da qual fará parte o mapeamento de lugares, edifícios e objetos patrimoniais, entrevistas e grupos focais para a sua interpretação, (micro) projetos indígenas e descolonizadores (TUHIWAI SMITH, 1999), a recuperação de topônimos indígenas e práticas de gestão tradicionais. Uma vez que as comunidades indígenas atribuem uma grande importância à sua história oral, ao invés de partirmos da habitual identificação da expressão física do patrimônio para depois desenvolver o seu plano de gestão, serão as histórias e valores camëntsá que constituirão o principal mecanismo para identificar esses sítios patrimoniais (POCOCK et al., 2015). Além disso, o projeto visa a treinar a comunidade em revitalizar ou criar as suas próprias ferramentas de gestão do patrimônio de acordo com a legislação nacional, mas desafiando esta última para se tornar mais inclusiva, igualitária e tolerante. Os objetivos do projeto incluem: documentar como os conceitos de patrimônio e valor patrimonial são definidos pelo povo Camëntsá; caracterizar os diferentes elementos ou categorias reconhecidas pela comunidade como possuidoras de valor patrimonial; conhecer quem detém a custódia e responsabilidade sobre lugares e 
objetos; compreender o que se entende por custódia desses elementos; entender como a comunidade se relaciona e identifica com objetos, sítios arqueológicos ou monumentos e o território; e treinar a comunidade para que esta possa autodesenvolver métodos e políticas de gestão e proteção do patrimônio que se adaptem às necessidades contemporâneas e estejam baseadas na sua cosmovisão. Esperamos também que o projeto estabeleça as bases para a criação de um museu gerido pela comunidade. No entanto, dentro de uma perspectiva intercultural, em vez de perpetuar as divisões já existentes, o objetivo é transformar o atual museu de Sibundoy de maneira a incluir os Camëntsá, levando ao diálogo, confrontação e colaboração entre os vários grupos na região.

\section{Conclusão}

Neste artigo foi abordada, de forma geral, a problemática entre a noção ocidental de patrimônio e a sua imposição num sentido top-down sobre os povos indígenas. As convenções da UNESCO e políticas nacionais não só reforçam dicotomias problemáticas em termos conceituais, como, na prática, desvinculam as comunidades dos seus patrimônios. Especificamente em relação a povos indígenas, tais mecanismos não estipulam que comunidades há muito excluídas retomem o controle e a gestão, ainda que partilhada, dos seus lugares e objetos patrimoniais, perpetuando a impossibilidade de emancipação das suas culturas. No que diz respeito à arqueologia, o fato de os Estados reclamarem para si a propriedade do "registro arqueológico", mesmo quando claramente relacionado com povos indígenas contemporâneos, revela uma percepção colonialista acerca destes.

O patrimônio está no seio de questões identitárias e comunitárias, de modo que os conflitos gerados para sua proteção e gestão são inúmeros, mas inevitáveis. No caso de comunidades indígenas como o povo Camëntsá, proteger o patrimônio é um ato contra-hegemônico, uma ação política de reconhecimento de uma cultura própria, da reivindicação de um território há muito perdido e de respeito pela sua cosmovisão.

Neste sentido, uma abordagem intercultural tem o potencial de contribuir positivamente para a gestão de conflitos relacionados com o patrimônio, o território ou o ambiente, e fornecer elementos que permitam fortalecer e capacitar as comunidades para que estas sejam ouvidas nos processos de gestão do seu patrimônio. A etnografia arqueológica é um espaço que permite trabalhar neste sentido, uma vez que dá ouvidos a diferentes grupos e está aberta a várias interpretações do passado.

A comunidade Camëntsá tem as suas próprias e legítimas noções de conservação e transmissão de conhecimento que podem ser usadas e adaptadas na gestão patrimonial. No entanto, é necessário um trabalho 
colaborativo e de compreensão mútua entre arqueólogos, museólogos e a comunidade. A gestão do patrimônio já não deve ser vista como um assunto que diga respeito apenas a especialistas e governantes, mas como um diálogo contínuo entre diferentes conceitos, interesses e abordagens.

\section{Agradecimentos}

Este trabalho não seria possível sem a colaboração e apoio da minha colega Jully Acuña Suárez e do meu supervisor Maarten Jansen. Um agradecimento especial tem de ser dirigido ao povo Camëntsá, sobretudo a mamá pastora Juajibioy Chindoy, taita Manuel Mavisoy e a Luísa, Ezequiel, Gerardo e Sebastian. Agradeço também a Raphaela Nawa pelas dicas e revisão do texto.

\section{Referências bibliográficas}

ACNUR. Hoja informativa sobre los pueblos indígenas en Colombia. El Trabajo del ACNUR con Pueblos Indígenas. 2011. Disponível em: http://www.acnur.org/t3/fileadmin/Documentos/Pueblos_indigenas/20 11 /Comunidades_indigenas_en_Colombia_-_ACNUR_2011.pdf . Acesso em: 4 maio 2018.

ALLEN, Harry; PHILLIPS, Caroline. Maintaining the Dialogue. Archaeology, Cultural Heritage and Indigenous Communities. In: PHILLIPS, Caroline; ALLEN, Harry (eds.). Bridging The Divide: Indigenous Communities And Archaeology Into The 21 st Century. Walnut Creek, CA: Left Coast Press, 2011 , p. 17-48.

ARAÚJO, Danielle. Etnografia da Técnica: A Produção de Cerâmica Andina. Espaço Ameríndio, v. 11 , n. 2, p. 48-70. 2017.

ARMSTRONG-FUMERO, Fernando; HOIL GUTIERREZ, Julio. Introduction. In: ARMSTRONG-FUMERO, Fernando; HOIL GUTIERREZ, Julio (eds.). Legacies of space and intangible heritage: archaeology, ethnohistory, and the politics of cultural continuity in the Americas. Boulder: University Press of Colorado 2017, p. 3-14.

BAPTISTA DA SILVA, Sergio. Apresentação: Saberes Hegemônicos e Contra-Hegemônicos em Contextos Latino-Americanos de (De)Colonialidade. Espaço Ameríndio, Porto Alegre, v. 11, n. 2, p. 4-12. 2017.

BERTACCHINI, Enrico; LIUZZA, Claudia; MESKELL, Lynn; SACCONE Donatella. The politicization of UNESCO World Heritage decision making. Public Choice, 2016. 
CABILDO INDÍGENA CAMËNTSÁ DE SIBUNDOY. Diagnostico Plan Salvaguarda Camëntsá. Bogotá:Ministerio del Interior Republica de Colombia, 2012.

CARDOSO, Thiago Mota; PARRA, Lilian Bulbarelli; MORDECIN, Isabel Fróes. Mapas em Movimento: Os (Des)Caminhos de uma Prática Cartográfica Junto aos Potiguara. Espaço Ameríndio, v. 11, n. 2, p. 71-111. 2017.

DANSAC, Yaël. Archaeological Ethnographies: analysing the relations between indigenous population and archaeological heritage in Tulum, Mexico. ASA 15 Symbiotic Anthropologies: Theoretical Commensalities and Methodological Mutualisms. Exeter University, UK, 2015.

GILBERT, Jérémie. Custodians of the Land: Indigenous Peoples, Human Rights and Cultural Integrity. In: LOGAN, William; CRAITH, Mairead Nic; LANGFIELD, Michele (eds.). Cultural diversity, heritage and human rights: intersections in theory and practice. Oxon: Routledge, 2010, p. 31-44.

GNECCO, Cristóbal. Paisaje con Golem. In: ArtEncuentro (ed.). Los Pueblos Originarios en los Museos. Propuestas Curatoriales y Museograficas (Vol. 1). Santiago: Museo Chileno de Arte Precolombino, 2012, p. 53-60.

GNECCO, Cristóbal. Heritage in Multicultural Times. In: WATERTON, Emma; WATSON, Steve (eds.). The Palgrave Handbook of Contemporary Heritage Research. Palgrave Macmillan, 2015, p. 263-280.

GNECCO, Cristóbal; AYALA, Patricia. ¿Qué hacer? Elementos para una discusión. In: GNECCO, Cristóbal; AYALA ROCABADO, Patricia (eds.). Pueblos Indígenas Y Arqueología En América Latina. Bogotá: Fundación de Investigaciones Arqueológicas Nacionales \& CESO, Facultad de Ciencias Sociales, Universidad de los Andes, 2010, p. 23-47.

GNECCO, Cristóbal; HERNÁNDEZ, Carolina. La historia y sus descontentos: estatuas de piedra, historias nativas y arqueólogos. In: GNECCO, Cristóbal; AYALA ROCABADO, Patricia (eds.). Pueblos Indígenas Y Arqueología En América Latina. Bogotá: Fundación de Investigaciones Arqueológicas Nacionales \& CESO, Facultad de Ciencias Sociales, Universidad de los Andes, 2010, p. 85-135.

GÓMEZ LÓPEZ, Augusto. El Valle de Sibundoy: El Despojo de Una Heredad. Los Dispositivos Ideológicos, Disciplinarios y Morales de Dominación. Anuario Colombiano de Historia Social y de la Cultura. Bogotá, n. 32, p. 51-73. 2005.

HAFSTEIN, Valdimar. Protection as Dispossession: Government in the Vernacular. In: KAPCHAN, Deborah (ed.), Cultural Heritage in Transit: Intangible Rights as Human Rights. Philadelphia: University of Pennsylvania Press, 2014. p. 25-57. 
HAMILAKIS, Yannis; ANAGNOSTOPOULOS, Aris. What is Archaeological Ethnography?. Public Archaeology: Archaeological Ethnographies, v.8, n. 2-3, p. 65-87. 2009.

HARRIS, Heather. Indigenous Worldviews and Ways of Knowing as Theoretical and Methodological Foundations behind Archaeological Theory and Method. In: BRUCHAC, Margaret, HART, Siobahn; WOBST, Hans M. (eds.). Indigenous Archaeologies. A Reader on Decolonization. Walnut Creek, CA: Left Coast Press, 201. p. 63-68.

HARRISON, Rodney. Beyond "Natural" and "Cultural" Heritage: Toward an Ontological Politics of Heritage in the Age of Anthropocene. Heritage and Society, v. 8, n. 1, p. 24-42. 2015.

HARRISON, Rodney. Heritage as Social Action. In: WEST, Susie (ed.). Understanding heritage in practice, Manchester: Manchester University Press, 2010a, p. 240-276.

HARRISON, Rodney. Multicultural and Minority Heritage. In: BENTON, Tim (ed.). Understanding Heritage and Memory. Manchester: Manchester University Press, $2010 \mathrm{~b}$, p. 164-201.

HOLLOWELL, Julie; NICHOLAS, George. Using Ethnographic Methods to Articulate Community-Based Conceptions of Cultural Heritage Management. Public Archaeology, v. 8, n. 2-3, p. 141-160. 2009.

ICOMOS. Carta de Coatepec: Patrimonio Inmaterial y Material como Categorías Inseparables del Patrimonio Cultural. Revista MEC-EDUPAZ, Cidade do México, n."V”, secção Documentalia. 2014.

IGLESIAS ALVIS, Oscar. Estructura, Redes y Rituales de la Comunidad Indígena Camëntšá de Sibundoy (Putumayo-Colombia). Tese (Doutorado em Antropologia) - Universidad de Salamanca, 2008.

INTERNATIONAL WORK GROUP FOR INDIGENOUS AFFAIRS (IWGIA); FOREST PEOPLES PROGRAMME (FPP). Promotion and protection of the rights of indigenous peoples with respect to their cultural heritage in the context of the implementation of UNESCO's World Heritage Convention. 2015.2 Disponível em: http://www.ohchr.org/Documents/Issues/IPeoples/EMRIP/CulturalHerita ge/IWGIA.pdf . Acesso em 4 maio 2018.

JANSEN, Maarten. Archaeology and Indigenous Peoples: Attitudes Towards Power in Ancient Oaxaca. In: BINTLIFF, John (ed.). A Companion to Archaeology. Blackwell Publishing, 2006. p. 235-252.

JANSEN, Maarten; RAFFA, Valentina. Tiempo y Comunidad. Herencias e Interacciones Socioculturales en Mesoamérica y Occidente. Leiden: Leiden University Press, 2015.

KARLSTRÖM, Anna. Preserving Impermanence. The Creation of Heritage in Vientiane, Laos. Tese (Doutorado em Arqueologia) - Uppsala University, 2009. 
KOSTANSKI, Laura; CLARK, lan. Reviving old Indigenous names for new purposes. In: KOCH, Harold; HERCUS, Luise (eds.). Aboriginal Placenames. Naming and Re-naming the Australian Landscape. Canberra: The Australian National University Press, 2009, p. 189-206.

KREPS, Christina. Non-Western Models of Museums and Curation in Crosscultural Perspective. In: MACDONALD, Sharon (Ed.). A Companion to Museum Studies. Oxford: Blackwell Publishing, 2006, p. 457-472.

LOGAN, William. Cultural diversity, cultural heritage and human rights: towards heritage management as human rights-based cultural practice. International Journal of Heritage Studies, v. 18, n.3, p. 231-244, 2012.

LONDOÑO, Wilhelm. Espíritus en Prisión: Una Etnografía del Museo Nacional de Colombia. Chungara: Revista de Antropología Chilena, v.44, n.4, p.733-745. 2012.

MARQUES MIRANDA, Marcelo. The Resurgence of the Heritage of Indigenous Peoples of Thailand in the Aftermath of Development. Nature \& Culture: Heritage in Context, 7th Annual Conference on Heritage Issues in Contemporary Society (Apresentação Oral). Praga, República Checa. 2016.

MAUREL, Chloé. Whose World Heritage? The problem with UNESCO's famous list. Equal Times. 2017. Disponível em: https://www.equaltimes.org/whose-world-heritage-theproblem?lang=en. Acesso em: 4 maio 2018.

MAVISOY, Willian. Kabëngbe Lware "Nuestro Territorio". El Reflejo del Cambio Espacial en la Tradición Oral Kamentsa del Valle de Sibundoy, Putumayo. In LÓPEZ, Carlos E.; OSPINA, Guillermo A. (eds.). Ecología Histórica. Interacciones Sociedad-Ambiente a Distintas Escalas SocioTemporales. 2008, Pereira: Universidad Tecnológica de Pereira, Universidad del Cauca, Sociedad Colombiana de Arqueología. p. 217-226.

MAY CASTILLO, Manuel; STRECKER, Amy. Heritage and Rights of Indigenous Peoples. Patrimonio y Derechos de los Pueblos Indígenas. Leiden: Leiden UniversityPress. 2017.

MENDIZÁBAL, Tomás; THEODOSSOPOULOS, Dimitrios. The Emberá, tourism and indigenous archaeology: "rediscovering" the past in Eastern Panama. MEMORIAS Revista digital de Historia y Arqueología desde el Caribe Colombiano, v.18, p. 88-114. 2012.

MESKELL, Lynn. Archaeological ethnography: conversations around Kruger National Park. Archaeologies v.1, n.1, p. 81-100. 2005.

MESKELL, Lynn. Human Rights and Heritage Ethics. Anthropological Quarterly, v. 83, n. 4, p. 839-860. 2010a.

MESKELL, Lynn. Ethnographic Interventions. In: LYDON, Jane; RIZVI, Uzma (eds.). Handbook of Postcolonial Archaeology. Walnut Creek, CA: Left Coast Press, 2010 b, p.445-458. 
MESKELL, Lynn; PREUCEL, Robert. Politics. In: MESKELL, Lynn; PREUCEL, Robert (eds.). A Companion to Social Archaeology. Malden: Blackwell Publishing, 2004. p. 316-334.

MINISTERIO DE CULTURA. Compendio de Políticas Culturales. Bogotá: Ministerio de Cultura, Republica de Colombia, 2010.

MINISTERIO DE CULTURA. Plan Especial de Salvaguardia del Bëtscnaté. Bogotá: Ministerio de Cultura, Republica de Colombia, (S/D). Disponível em: http://studylib.es/doc/8231297/lea-pes-aqu\%C3\%AD---ministeriode-cultura. Acesso em 4 maio 2018.

NAÇÕES UNIDAS. Declaração sobre os Direitos dos Povos Indígenas. Nações Unidas, 2007.

POCOCK, Celmara; COLLETT, David; BAULCH, Linda. Assessing stories before sites: identifying the tangible from the intangible. International Journal of Heritage Studies. DOI:10.1080/13527258.2015.1040440. 2015.

RAFFA, Valentina. Comunicar entre culturas. In: JANSEN, Maarten; RAFFA, Valentina (eds.). Tiempo y Comunidad. Herencias e Interacciones Socioculturales en Mesoamérica y Occidente. Leiden: Leiden UniversityPress, 2015. p. 47-52.

RODRIGUEZ URIBE, Natalia; RODRIGUEZ URIBE, Daniela. Nuevas Voces Indígenas: La Salvaguardia Del Patrimonio Inmaterial En Colombia Y La Reafirmación de Los Derechos Culturales. Letras Jurídicas, v.18, v.1, p. 161-95. 2013.

SAMUELS, Kathryn; RICO, Trinidad. Heritage Keywords. Rhetoric and Redescription in Cultural Heritage. Boulder: University Press of Colorado, 2015.

SCHENSUL, Stephen; SCHENSUL, Jean; SINGER, Merrill; WEEKS, Margaret; BRAULT, Marie. Participatory Methods and Community-Based Collaborations. In: BERNARD, H. Russell; GRAVLEE, Clarence C. (eds.). Handbook of Methods in Cultural Anthropology. Lanham: Rowman \& Littlefield, 2015, p.185-212.

SCHRAMM, Katharina. Heritage, Power and Ideology. In: WATERTON, Emma; WATSON, Steve (eds.), The Palgrave Handbook of Contemporary Heritage Research. Palgrave Macmillan, 2015, p. 442-457.

SINGH, Rana. The Contestation of Heritage: The Enduring Importance of Religion. In: GRAHAM, Brian; HOWARD, Peter (eds.). Ashgate Research Companion to Heritage \& Identity. Aldershot Hamp. \& London: Ashgate Pub, 2008, p. 125-141.

SMITH, Laurajane. Uses of Heritage. London and New York: Routledge, 2006.

TUHIWAI SMITH, Linda. Decolonizing Methodologies. Research and Indigenous Peoples. London and New York: Zed Books. 1999. 
UNESCO. Convenção para a Proteção do Patrimônio Mundial, Cultural e Natural. Paris: UNESCO, 1972.

UNESCO. Convenção para a Salvaguarda do Património Cultural Imaterial. Paris: UNESCO, 2003.

WINTER, Tim. Clarifying the Critical in Critical Heritage Studies. International Journal of Heritage Studies, v.19, n. 6., p. 532-545. 2013.

WOBST, H. Martin. Indigenous Archaeologies: A Worldwide Perspective on Human Materialities and Human Rights. In: BRUCHAC, Margaret; HART, Siobahn; WOBST, H. M. (eds.). Indigenous Archaeologies. A Reader on Decolonization. Walnut Creek, CA: Left Coast Press, 2010, p. 17-28. 